\title{
TORCICOLO. POSIÇÃO VICIOSA DE CABEÇA
}

\author{
OCULAR TORTICOLLIS. COMPENSATORY HEAD POSTURES
}

Harley E.A. Bicas

\begin{abstract}
Docente do Departamento de Oftalmologia e Otorrinolaringologia da Faculdade de Medicina de Ribeirão Preto - USP.
CoRRESPONDÊNCIA: Departamento de Oftalmologia e Otorrinolaringologia da Faculdade de Medicina de Ribeirão Preto - USP. - 14.048-090 Ribeirão Preto - SP.
\end{abstract}

BICAS HEA. Torcicolo. Posição viciosa de cabeça. Medicina, Ribeirão Preto, 33: 64-72, jan./mar. 2000.

RESUMO: Torcicolo e posição viciosa da cabeça (PVC) são termos empregados para descrever a condição de um desvio cefálico relativamente ao tronco. Isso pode ser devido a uma causa ortopédica (defeitos das vértebras cervicais, contraturas musculares) ou a uma ocular, representando ajustamentos para compensação de desequilíbrios oculomotores (estrabismos ou heteroforias incomitantes, bloqueio de nistagmos, fixação com um olho mal posicionado na órbita, blefaroptoses e outras menos freqüentes). A quantificação da PVC suscita uma análise sobre problemas conceituais (critérios e referenciais) e operacionais a ela relacionados.

O diagnóstico diferencial entre causas ortopédicas e oculares é determinado por manobras de movimentação passiva da cabeça relativamente ao tronco e por exame do equilíbrio oculomotor (teste de cobertura, rotações oculares). Comprovando-se um fator causal ocular, sua correção é buscada por uma cirurgia que lhe seja específica, basicamente a de reposicionamento adequado do olho fixador em sua órbita e de anulação do ângulo de um estrabismo, se houver. Vários exemplos práticos são comentados.

UNITERMOS: Transtornos da Motilidade Ocular. Rotação Ocular. Estrabismo.

\section{CONSIDERAÇÕES SOBRE TERMOS E SEUS SIGNIFICADOS}

O termo torcicolo, cujo significado etimológico é o de "pescoço" (colo) "torto", aplica-se à condição em que a cabeça fica mal posicionada relativamente ao tronco. Daí, também, o uso de posição viciosa de cabeça (PVC) para nomear esse achado clínico. Entretanto, ainda que esses termos tenham sido corriqueiramente usados como sinônimos, uma análise mais rigorosa de suas extensões permite distingui-los. De fato, o pescoço sustenta a cabeça sobre o corpo e a articula em seus movimentos de orientação espacial, tanto no que concerne à ação gravitacional quanto no que se refere à localização sensorial (visual e auditiva) de estímulos circunjacentes. Assim, para privilegiar a percepção do ambiente, a cabeça se situa, relativamente ao corpo, de modo que objetos sejam vistos e sons ouvidos com a melhor qualidade discriminativa, requerendo-se para isso ampla liberdade de movimentos. Ora, justamente quando se perde essa liberdade de ajustamentos posicionais é que se aplicam os termos "torcicolo" ou "posição viciosa de cabeça".

Parece, pois, mais apropriado que "torcicolo", pondo ênfase ao significado de "pescoço torto", seja usado quando existem causas anatômicas para justificá-lo (por exemplo, defeitos de articulações das vértebras da coluna cervical, contratura de um músculo esternocleidomastoideu). A posição inadequada da cabeça relativamente ao tronco é, portanto, mera conseqüência. Por outro lado, "posição viciosa de cabeça" insinua que o problema não é (primariamente) do pescoço, mas da "cabeça" (ver, ouvir), cuja posição é "viciosa" (isto é, defeituosa) e não casual. A constância de uma postura é, aliás, o que caracteriza o "vício". Claro que, com o passar do tempo, podem surgir deformidades do pescoço, dando então ensejo a que volte a se aplicar a denominação "torcicolo" (mas, en- 
tão, como conseqüência da PVC e não como sua causa). Enfim, se a fundamentação de uma anomalia postural da cabeça, relativamente ao tronco, for funcional, determinada, por exemplo, por uma necessidade de adequação visual, parece preferível o termo PVC (e não torcicolo).

\section{CONDIÇÕES VISUAIS DETERMINANTES DE UMA PVC}

Como já adiantado, o conhecimento do espaço circunjacente (uma discriminação subjetiva, egocêntrica) é feito pelos sentidos (visual, auditivo, tátil, térmico) dos quais os de atributos mais apreciados (visão, audição) dependem de sensores exclusivamente fixados à cabeça. Deve-se, pois, direcioná-la para a melhor percepção de um som. O escrutínio visual do espaço não é totalmente dependente desses ajustamentos posicionais cefálicos, já que os olhos podem se mover; mas é bem ajudado por aqueles. Realmente, rotações oculares para a direita e esquerda, para cima e para baixo, ou a outras localizações intermediárias, são limitadas (no máximo uns $50^{\circ}$, em apenas algumas dessas direções) e quando deslocamentos mais amplos são necessários, a cabeça é movida para suplementar (ou substituir) os dos olhos. Aliás, as rotações oculares costumeiras ficam limitadas a cerca de uns $15^{\circ}$, suscitando-se movimentos da cabeça e do corpo para situar os olhos em direcionamentos ao objeto de atenção visual.

\subsection{Compensação de um estrabismo}

Uma das condições mais freqüentes de uma PVC é a do ajustamento dos olhos para que se compense um estrabismo incomitante na direção em que ele é menor. Por exemplo, suponha-se uma diminuição de abdução do OD (determinada por um processo restritivo dessa rotação, ou por uma paresia de RLD) de modo que o desvio dos eixos visuais (uma esotropia) seja grande no olhar para a direita (quando tal rotação, deficiente, é suscitada), menor no olhar em frente e ainda mais reduzido (chegando a se tornar nulo, ou tão pequeno que possa ser compensado por mecanismos binoculares fusionais) no olhar para a esquerda (onde os mecanismos de produção da rotação afetada estão total ou grandemente desativados). Assim, no olhar para a esquerda, com olhos adequadamente posicionados, não há diplopia nem confusão, enquanto, nas outras posições, esses distúrbios de orientação visual aparecem. Na verdade, a posição dos olhos voltados "para a esquerda", isto é, relativamente às órbitas (abdução do olho esquerdo e adução do direito) pode ser mantida no "olhar em frente" (do corpo), se a cabeça for convenientemente girada, no caso, para a direita (Figura 1).

Note-se que os eixos visuais ficam paralelos (o estrabismo é neutralizado) quando as posições oculares respectivas estiverem deslocadas $\mathbf{h}$ graus à esquerda das órbitas (c), condição equivalente à que se dá quando a magnitude da rotação da cabeça for idêntica a $\mathbf{h}$ (em d): aí, o estrabismo achar-se-á também compensado, mas, agora, o olhar é dirigido "para frente" do corpo (não da cabeça).

Espera-se, então, que para compensar um estrabismo (e garantir visão binocular normal) a cabeça esteja sempre girada em direção da ação rotacional ocular comprometida.Uma regra mnemônica para relacionar a PVC a uma paresia muscular que a tenha produzido é a de que o músculo se "desprende" do olho (e por isso não o gira) e se "prende" à cabeça (rodando-a, para compensar o estrabismo). Outra regra é a de que a cabeça se situe de modo que o olho esteja na posição de máxima ação do músculo antagonista ao afetado, para fixar um objeto "em frente" do corpo. A Tabela I relaciona essas condições.

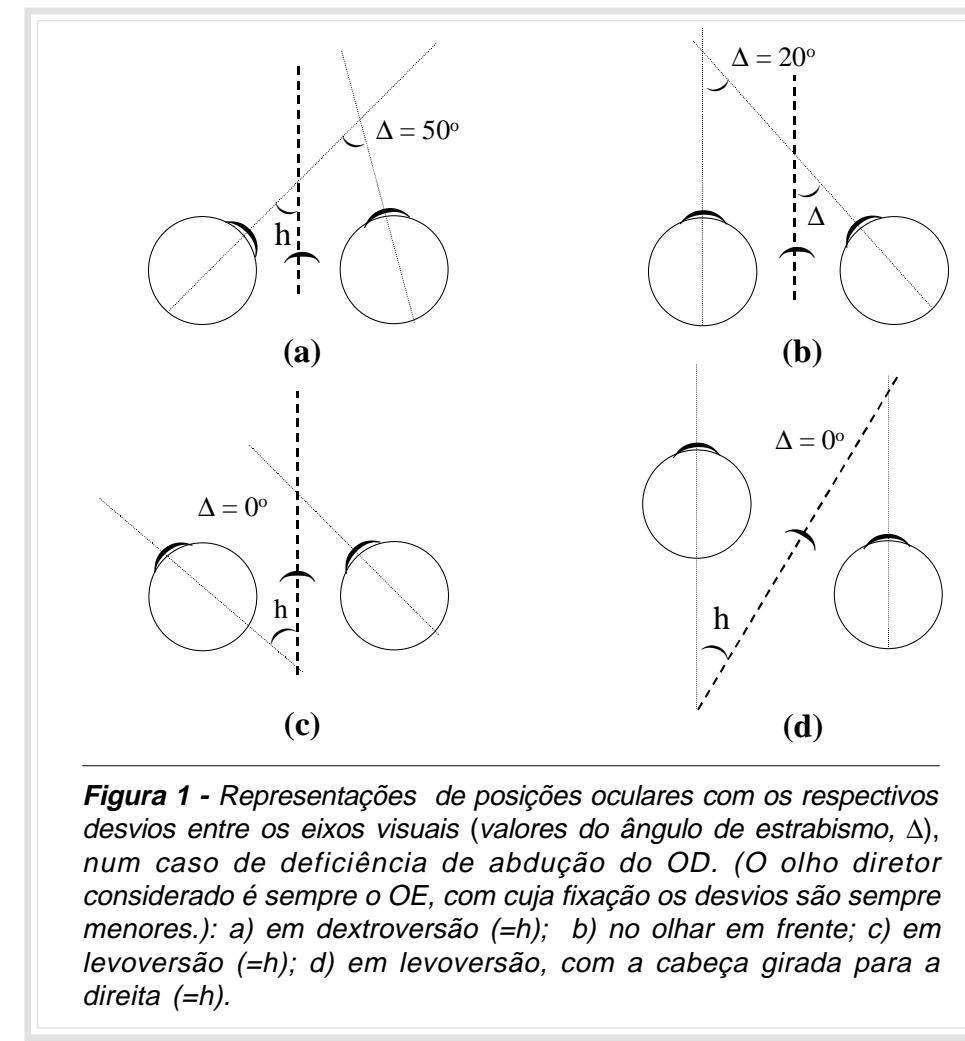




\begin{tabular}{|lll|}
\hline \multicolumn{3}{|l|}{$\begin{array}{l}\text { Tabela I - Relação entre PVC } \\
\text { músculo parético causador }\end{array}$} \\
\hline $\begin{array}{c}\text { Rotação da } \\
\text { cabeça }\end{array}$ & $\begin{array}{c}\text { Músculo } \\
\text { afetado }\end{array}$ & $\begin{array}{c}\text { Estrabismo }\left(^{*}\right) \\
\text { (em frente) }\end{array}$ \\
\hline Para a direita & RLD & ETOD \\
& RME & XTOE \\
\hline Para a esquerda & RMD & XTOD \\
& RLE & ETOE \\
\hline Para cima & RSD & hTOD \\
& RSE & hTOE \\
\hline Para baixo & RIE & HTOE \\
& RID & HTOD \\
\hline Inclinada p/ D & OSE & EcTOE \\
& OID & IcTOD \\
\hline Inclinada p/ E & OIE & IcTOE \\
& OSD & ECTOD \\
\hline
\end{tabular}

(*) Usa-se a representação hT para significar hipotropia; EcT para exciclotropia e IcT para inciclotropia, além das convencionais (HT, hipertropia; ET, esotropia e XT, exotropia). mam às suas ações (principalmente) verticais, quanto os oblíquos têm funções horizontais e verticais que se superpõem às suas (principalmente) torcionais. Desse modo, uma hipofunção do OSD dá, geralmente, além de uma PVC principalmente inclinada para o ombro $\mathrm{E}$, uma depressão do mento (pela falência da ação abaixadora desse músculo) e, eventualmente, uma rotação (discreta) da cabeça para a direita (pela falta do componente abdutor desse músculo, aliás pequeno), isto é, numa posição em que seria máxima a ação do OID (o antagonista direto do OSD). Assim, também, uma avulsão do RSD daria, além de uma cabeça rodada para trás (cima), isto é, olhos para baixo, uma rotação dela para a esquerda (pela ausência da ação adutora do RSD), isto é, olhos para a direita; e levemente inclinada para a esquerda (por falta de sua inciclotorção), isto é, olhos em dextrociclotorção. Exatamente a posição em que se propõe testar o RID (o antagonista direto do RSD) (Figura 3). As Figuras 2 e 3 e a Tabela II ilustram as relações de PVC e suas causas.
Resulta, pois, que uma rotação horizontal da cabeça (para a direita ou esquerda) indicará compensação de um desvio horizontal, sua inclinação (para um dos ombros), a compensação de um desvio torcional e a elevação ou depressão (geralmente dita "do mento"), a de um vertical. Mas as evocações etiopatogênicas de músculos paréticos como possivelmente causadores da PVC não são todavia seguras, já que processos restritivos de suas ações (então normais) podem, similarmente, estar dificultando ou impedindo a rotação respectiva. Diferenciações diagnósticas das causas devem ser feitas com os testes de duções passivas (para comprovar ou excluir restrições) e das forças geradas (para comprovar ou excluir paresias ou paralisias).

$\mathrm{Na}$ verdade, PVC tão puras como as sugeridas pela Tabela I não são comuns, a não ser em casos de hipofunções de retos laterais, ou de processos restritivos da adução (por exemplo, como resultado de cirurgias de estrabismo, ou por desinserção de um reto medial após remoção do pterígeo, etc.). Tanto os retos verticais têm componentes horizontais e torcionais que se so-

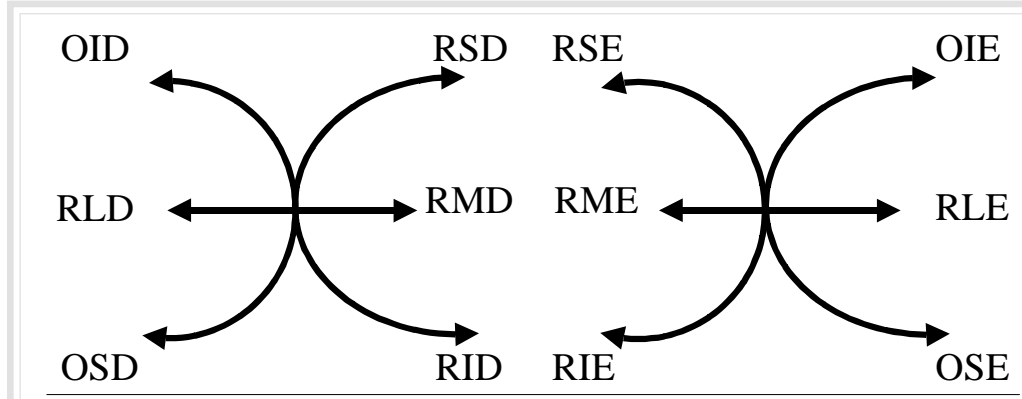

Figura 2 - Esquema de direções para as quais a cabeça é rodada em casos de hipofunções musculares isoladas.

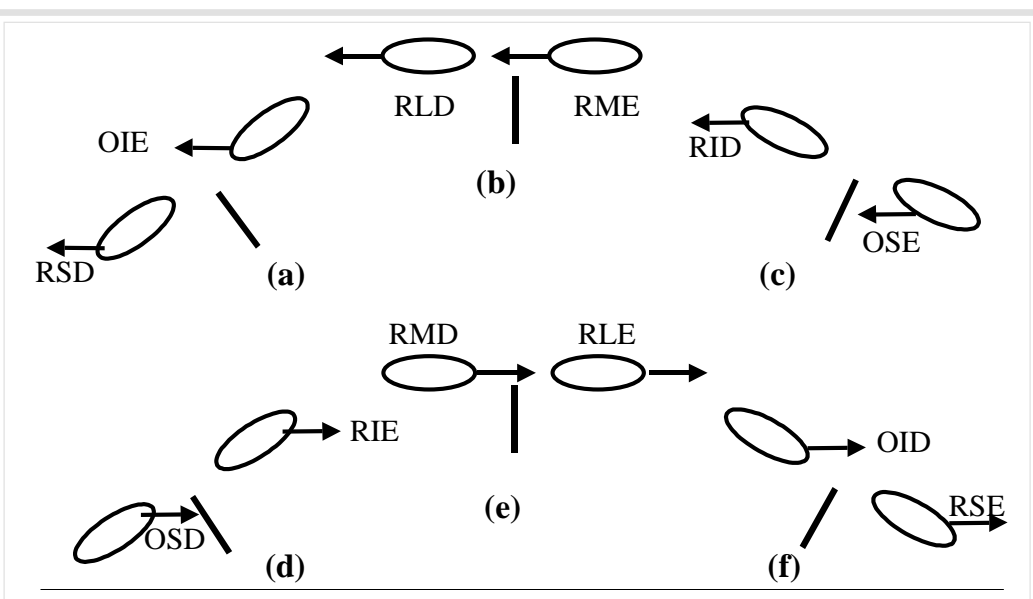

Figura 3 - Posições esquemáticas (as elipses representando as fendas palpebrais abertas; o pequeno traço entre elas, o eixo vertical do nariz; e a flecha indicando a posição do olhar) em que cada músculo ocular externo é maximamente acionado. Note-se que cada posição, por exemplo, a do RSD, com o olhar para a direita, acima e em inciclotorção (para a E) é exatamente oposta à da PVC causada pela hipofunção do antagonista direto (RID). 


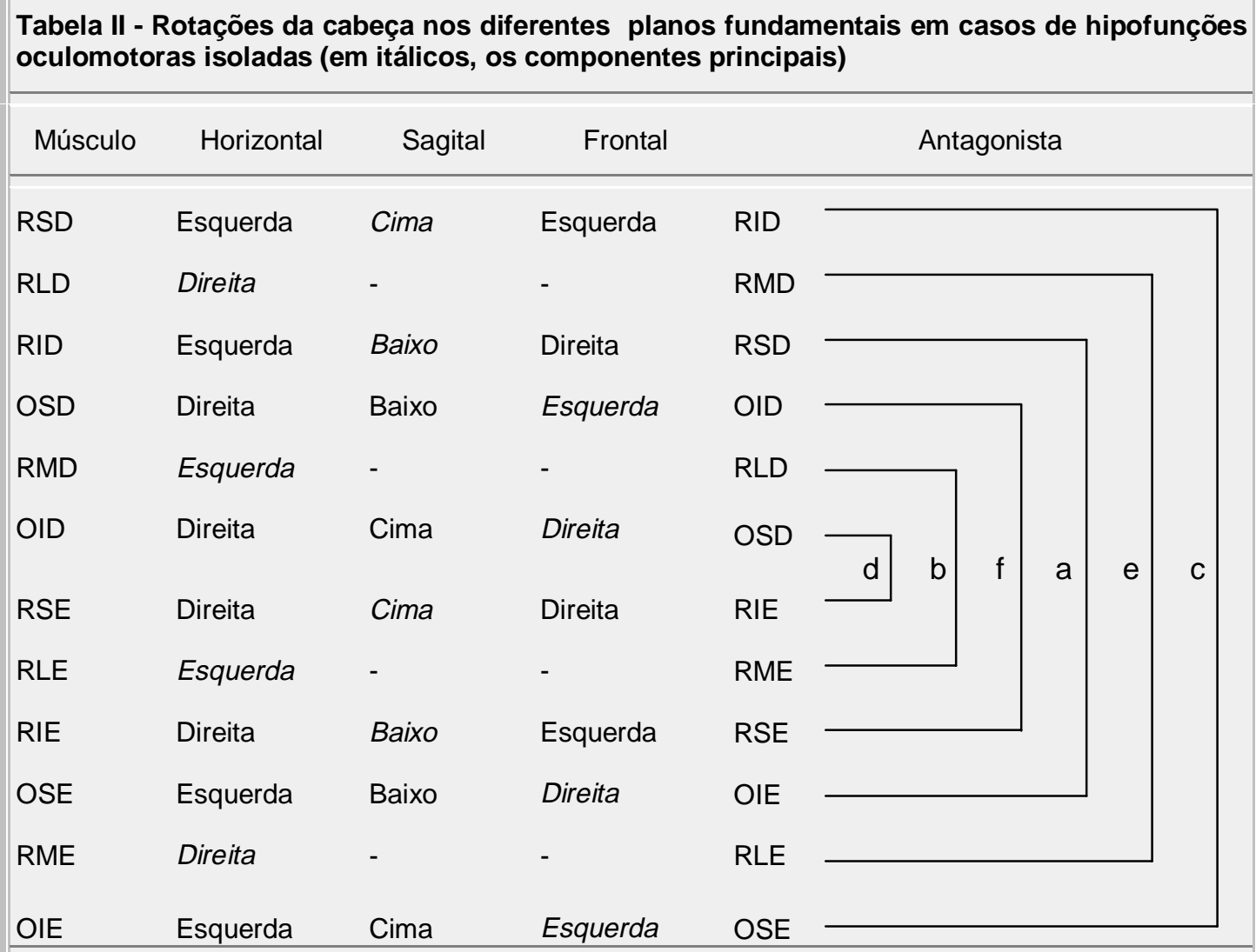

\subsection{Variações em A ou $V$}

Um caso particular desses desvios incomitantes é o das variações do desvio horizontal em padrões "A" ou "V", mesmo que, em posição primária, não exista um estrabismo, ou que ele seja compensado (heteroforia). Assim, esodesvios em $\mathrm{V}$ ou exodesvios em A (menores no olhar para cima) produzirão uma PVC (defensiva) fletida. Ao contrário, esodesvios em $\mathrm{A}$ ou exodesvios em $\mathrm{V}$ (menores em infraversão) acarretarão uma PVC em extensão.

\subsection{Bloqueio de um nistagmo}

A impossibilidade de os olhos se manterem estaticamente posicionados ao longo do tempo, numa determinada direção, o nistagmo, pode se manifestar com variadas modalidades, quer na dependência da frequiência e amplitude dos movimentos, quer quanto à posição em que eles aparecem e sua forma (pendular, irregular, com fases rápida e lenta, etc.). Em alguns tipos, geralmente os que se manifestam com uma fase lenta e outra rápida ("jerky"), há variações da intensidade do nistagmo com a posição do olhar, chegando-se a uma em que ele se reduz acen- tuadamente ou se anula. Essa posição, a de bloqueio do nistagmo, favorece então a discriminação visual (pela melhor estabilidade ocular) e é adotada pela pessoa. Assim, por exemplo, nistagmos com fase rápida para a esquerda, bloqueiam-se em dextroversão. A cabeça será, pois, girada para a esquerda (de modo a promover a dextroversão relativamente às órbitas, olhar em frente do corpo).

Em esotropias congênitas, conhecidas como "Síndrome de Ciancia", é comum o achado de fixação cruzada; isto é, olhar para a direita com o olho esquerdo (em adução) e olhar para a esquerda com o olho direito (em adução). Na verdade, nessas crianças ocorre um nistagmo de fixação para o lado da abdução de cada olho, de modo que a posição de adução seria meramente uma defesa para que a instabilidade oculomotora então se anulasse. Daí a terminologia usada por europeus para descrever esse quadro: síndrome do "nistagmo bloqueado". Ressalte-se que a PVC para bloqueio de um nistagmo manifesta-se sem qualquer razão para obtenção da binocularidade (como no caso da PVC para neutralização de um estrabismo), continuando a ocorrer mesmo em pacientes monoculares. 


\subsection{Fixação com olho desviado}

Em certos casos, a fixação se faz com um olho que não pode direcionar seu eixo visual "em frente" (da cabeça). Isso pode se dar por uma cicatrização que mantenha tal olho em posição desviada (relativamente à sua órbita), ou por uma paralisia de um músculo com contratura de seu antagonista, etc. Semelhantemente ao caso da PVC para bloqueio de um nistagmo, aparecerá a que permite a fixação com esse olho "em frente" do corpo, mesmo em casos em que o paciente possua apenas um olho.

\subsection{Blefaroptoses totais}

Quando bilaterais, obrigam seus portadores a manter a cabeça em extensão para que logrem ver pela abertura palpebral remanescente.

\subsection{Outras}

Há ainda a possibilidade de que PVC por outras causas visuais apareça, como a de uma posição (paradoxal) em que o estrabismo se torne maior. Realmente, se não for conseguida sua neutralização, em qualquer das posições oculares, a convivência com a diplopia em que as imagens estejam mais distantes, ou a supressão dela nessas condições, se torna mais fácil. Ora, diplopia com imagens mais separadas significa desvio de magnitude maior, que seria então buscado pela PVC. Assim, numa paresia de RLD, com desvios de, por exemplo, $15^{\Delta}$ em levoversão (sem compensação), $25^{\Delta} \mathrm{em}$ posição primária e $40^{\Delta} \mathrm{em}$ dextroversão, seria esta a situação posicional procurada: a PVC girada para a esquerda (portanto oposta à normalmente esperada em tal condição) poderá surgir. Esta não é, todavia, uma resposta usual.

Assim, também, menciona-se a possibilidade de uma PVC para melhorar a qualidade visual em um astigmatismo inclinado e "grande", ou para fugir a uma opacificação central "pequena" dos meios transparentes (em ambos os casos, quando a afecção ocorre num olho único, ou fixador), etc.

\section{QUANTIFICAÇÕES}

\subsection{Conceitos}

A ausência de um conjunto de critérios para definir o significado de posição "correta" da cabeça, a partir da qual seus possíveis desvios são medidos, torna essas quantificações difíceis e sem rigor. De fato, o problema começa com a própria caracteriza- ção do ponto zero do equilíbrio oculomotor, a posição primária do olhar. Ela é definida, teoricamente, como a posição de coincidência dos sistemas de eixos oculares e orbitais. Na prática, essa coincidência é concebida quando o sujeito olha "em frente" com a "cabeça ereta". Mas a aparente simplicidade dessa proposição logo conduz a delicados problemas a respeitados termos de sua construção e o modo de operálos. Em verdade, essa proposição "prática" é extremamente primitiva e insuficiente, por tentar reduzir o sistema de eixos oculares a um único, o visual ou ântero-posterior do olho (olhar "em frente"), pressupondo que o vertical e o horizontal (transversal) coincidam com a vertical e,ou a horizontal objetivas (isto é, que não haja torção); e, além disso, supondo, igualmente, que um único plano da cabeça, o horizontal (contendo o eixo longitudinal, ântero-posterior, e o transversal), baste para posicioná-la ("ereta") sem considerar a possibilidade de que ela esteja girada em torno de um eixo vertical (para a direita, ou para a esquerda) relativamente ao corpo. Obviamente, poder-se-ia adicionar à proposição original mais um termo, isto é, "olhar em frente, com a cabeça ereta e em frente" mas isso introduz um novo sistema de eixos, o do corpo, relativamente ao qual a posição cefálica é referida ("em frente" dele).

Ora, voltando ao sistema de eixos oculares, não é possível conhecer torção, a não ser por informações do paciente: faltam parâmetros para conhecer, sem elas, qual seja o eixo ocular vertical e, ou o horizontal transversal. Conseqüentemente, a posição primária do olhar não pode, rigorosamente considerando, ser estabelecida de modo objetivo. Assim, embora uma PVC possa ter sua origem como um processo de neutralização de um estrabismo (inclusive para evitar torções), não há como medi-la "objetivamente" a partir dele, isto é, a não ser com a informação de que ela (PVC) seja totalmente "compensatória" .

De qualquer modo, como PVC não refere o olho à cabeça (estrabismo), mas cabeça ao corpo, será possível uma medida objetiva de posições de uma relativamente ao outro, embora, ainda assim, não absolutas. Para elas (quantificações absolutas), isto é, determinações de que parte está efetivamente desviada, um sistema referencial "absoluto" (o gravitacional terrestre) será também requerido. A Figura 4 exemplifica as possíveis combinações entre posições viciosas da cabeça, do pescoço (coluna cervical) e do tronco (coluna vertebral torácica e lombar). 


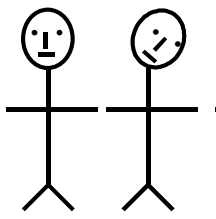

(a)

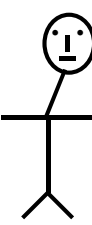

(b) (c)

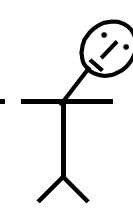

(e)

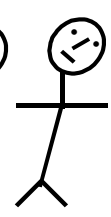

(f)

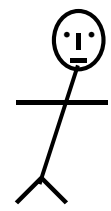

(g)

(h)
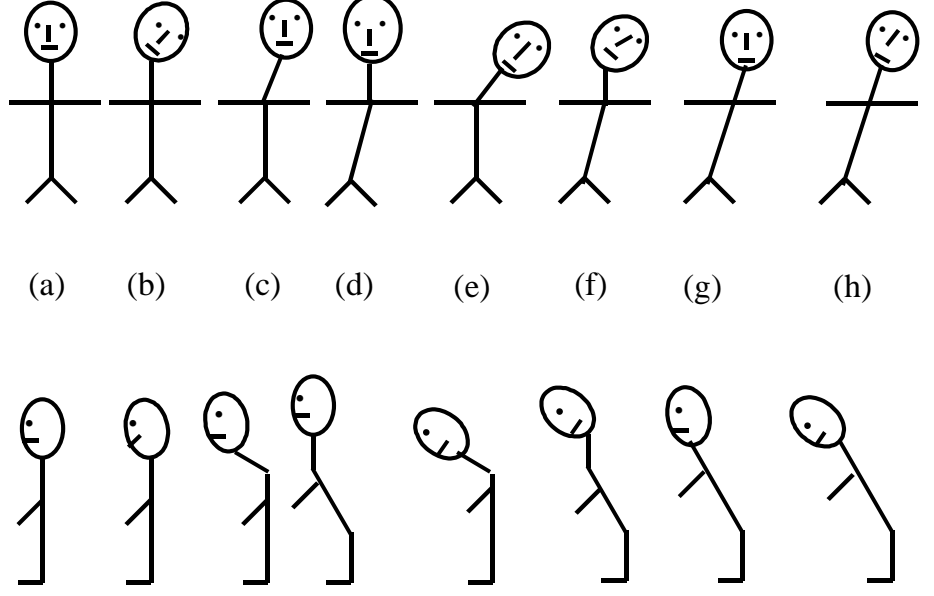

Figura 4 - Esquematizações de relações da cabeça e tronco, conforme suas articulações pelo pescoço, no plano frontal (acima) e no sagital (abaixo): (a): normal; (b): PVC típica; (c) posição viciosa do pescoço (sem desvios da cabeça relativamente ao tronco); (d): posição viciosa do tronco; (e): PVC por desvio do pescoço relativamente ao tronco; (f): PVC e do tronco; (g): cabeça ereta apesar de desvios do pescoço e tronco; (h): cabeça, pescoço e tronco todos com iguais desvios absolutos. haste $\mathrm{F}$ deve ser, então, posta com sua direção coincidente à de "marcos referenciais", isto é, pontos pelos quais se padronize o que seja uma linha vertical ou horizontal normal da cabeça (Figura 5). Para uma "vertical" (a qual se fará coincidir a direção da haste F) pode-se escolher a linha que passe pelo meio do queixo (Q) e entre as narinas $(\mathrm{N}) \mathrm{e}$, ou os cantos internos das rimas palpebrais (E). Entretanto, nem sempre esses pontos são unidos por uma única linha (Figura 6) e, por outro lado, mesmo que estivessem alinhados, não fica implícito que a direção deles coincida com a de uma vertical objetiva, devido a assimetrias faciais. A tomada de um outro padrão referencial, por exemplo, o de uma linha horizontal que passe pelos cantos externos (C) ou internos dos olhos ou entre os orifícios auriculares (A) e sobre a qual uma perpendicular pudesse ser traçada para coincidir com a linha $P$, não garante que isso seja objetivado.
As posições da cabeça podem portanto ser objetivamente registradas, em termos relativos (conforme o direcionamento do pescoço) e absolutos (referentemente à vertical e, ou horizontal "objetivas"). Assim, as posições viciosas absolutas da cabeça (desviadas relativamente a referenciais da gravidade terrestre) são as dos esquemas b, e, f, h; mas as posições de desvio relativo (ao pescoço) são as que dependem de possível ajustamento visual: b e f (compensando um desequilíbrio oculomotor) c e $\mathbf{g}$ (compensando um problema ortopédico); enquanto as de fixação entre cabeça e pescoço $(\mathrm{d}, \mathrm{e}, \mathrm{h})$ representam, necessariamente, problemas ortopédicos do tronco (d) ou da articulação do pescoço com ele e com a cabeça (e, h).

\subsection{Operações}

\subsubsection{Plano frontal}

Medições de inclinações de cabeça para um dos ombros podem ser feitas a partir de uma direção vertical (por exemplo, uma linha de prumo, P) considerando-se o ângulo que uma outra, F, fizer com ela. A operação requer um instrumento em que uma haste fixa seja o referencial objetivo (direção P) e uma outra, móvel, corresponda à direção $\mathrm{F}$, ambas convergindo para o centro de um transferidor (para a medida do ângulo) onde são articuladas (M, Figura 5). A

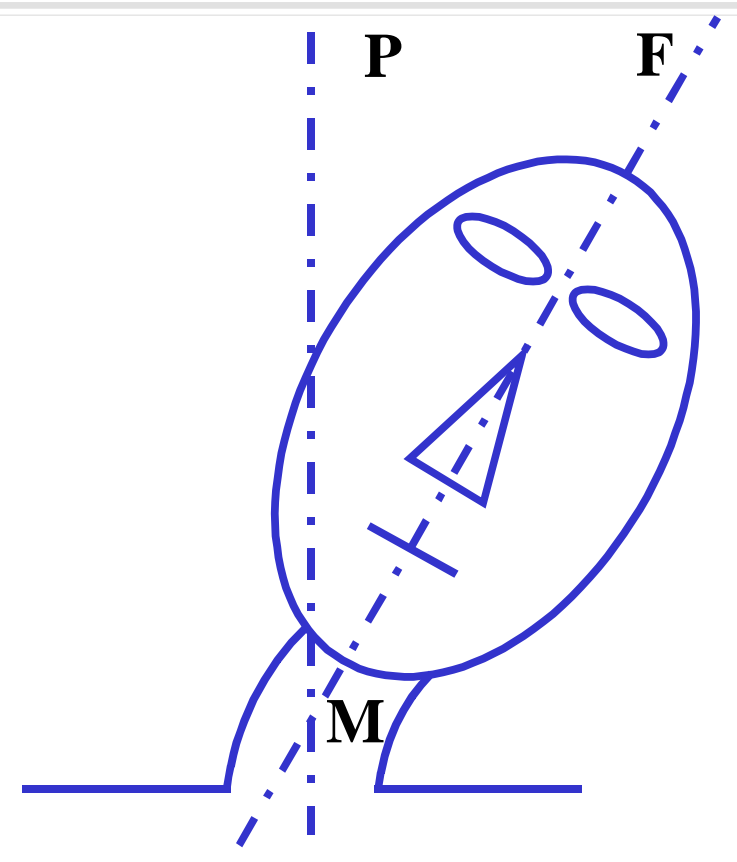

Figura 5 - Esquema de medição de uma inclinação da cabeça para o ombro esquerdo (por observação de sua posição no plano frontal). Duas hastes articuladas em $M$ (por exemplo, o centro de um transferidor), uma ajustada à linha de prumo $(P)$, ou qualquer outra referência à "vertical objetiva" (como a VV, na figura 6) e outra (F), acompanhando a orientação do eixo vertical da cabeça, darão $o$ angulo de desvio (PMF) 


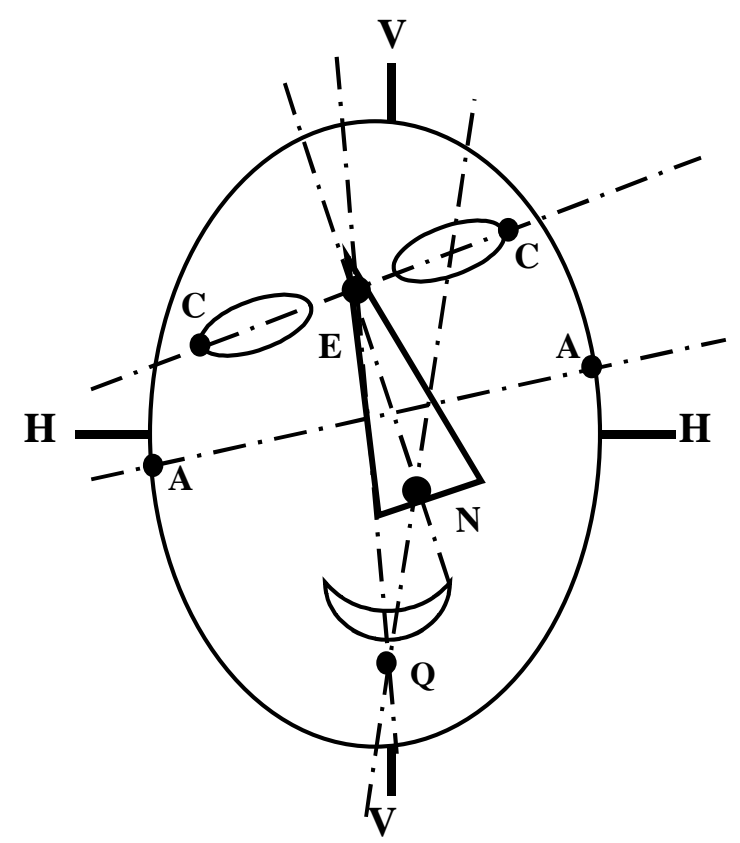

Figura 6 - Linhas de referência para situação da cabeça "aprumada"(linhas $E Q, E N, N Q$ ) e "nivelada" (linhas $A A$ e CC) no plano frontal. Nem sempre as linhas verticais são coincidentes entre si ou com a vertical objetiva (VV), assim como, também, as linhas horizontais podem não coincidir com a horizontal objetiva $(\mathrm{HH})$, pelas assimetrias faciais.

\subsubsection{Plano sagital}

Para medidas de elevação ou abaixamento da cabeça, os padrões referenciais são ainda mais discutíveis. As construções de uma linha vertical e, ou de uma horizontal que possam representar qual deva ser a posição "ereta" da cabeça tornam-se igualmente problemáticas: nada assegura que, para uma dada face, uma vertical que passe, por exemplo, tangente à testa (T) e ao mento (Q), ou uma horizontal passando pela ponta do nariz ou por uma das narinas $(\mathrm{N})$ e pelo orifício auricular (A) sejam ortogonais entre si e, ou coincidentes à vertical ou à horizontal "objetivas", respectivamente (Figura 7).

\subsubsection{Plano horizontal}

Mais difícil ainda fica a escolha de pontos no plano horizontal, para que se aquilatem rotações da cabeça para a direita ou para a esquerda: não é possível um exame pela parte inferior da cabeça e o pela parte superior, geralmente, é dificultado por penteados; ou pela posição em que o observador deveria ficar. Na verdade, a visada frontal da face pode sugerir que, estando um lado (por exemplo, uma orelha) mais frontalizado que outro, haja uma rotação da cabeça em torno do eixo vertical. De qualquer modo, tecnicamente, a medida seria extremamente complicada. A alternativa fica sendo a de posicionar no plano horizontal, sobre a cabeça, a haste P numa direção suposta à da cabeça em frente (por exemplo, numa direção perpendicular a uma linha passando pelas apófises umerais) e a $\mathrm{F}$ coincidente à direção em que "ela" (?) se encontra... Muito pobre.

\subsubsection{Conclusão}

Medidas rigorosas de PVC não podem ser feitas, pelas dificuldades conceituais e operacionais a elas inerentes. Felizmente, não são todavia imprescindíveis, já que desvios discretos do que seria normalidade (um padrão de caracterização tão problemática) ficam, igualmente, pouco notados. De resto, a eliminação de uma PVC tem mais um caráter qualitativo (tentativa de erradicação de suas causas; por exemplo, um estrabismo) que quantitativo; pois se espera que, se ela, causa, puder ser aproximadamente corrigida (ainda que não totalmente), ajustamentos binoculares fusionais cheguem a compensar o que eventualmente faltar para uma "perfeita" conjugação entre olhos, cabeça e corpo. Em resumo: mede-se o ângulo de um estrabismo, ou o deslocamento dos olhos em que se

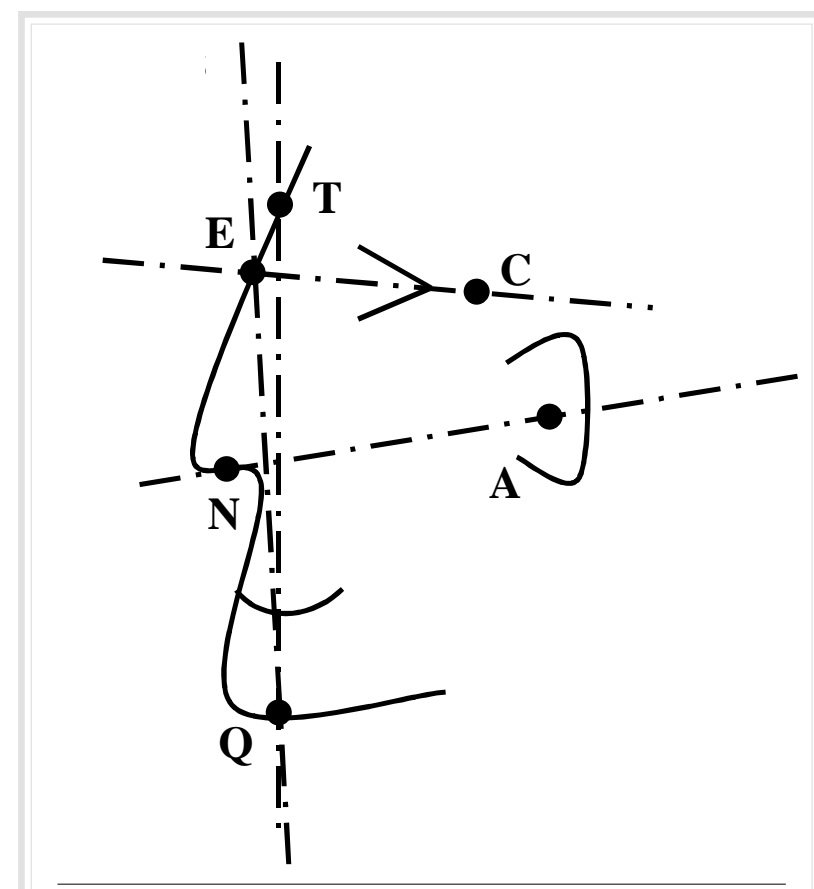

Figura 7 - Linhas de referência para situação da cabeça "aprumada" (linhas QE ou QT) e "nivelada" (linhas EC ou AN) no plano sagital. Tais linhas não são necessariamente perpendiculares entre si. 
dá o bloqueio de um nistagmo e procura-se corrigir, com a eliminação de uma dessas causas, a PVC decorrente. (Claro que o problema das medidas rigorosas de um estrabismo é remetido às considerações do que seja o "zero" oculomotor, a posição primária em que os olhos devam estar. Elas também não chegam a ser costumeiramente possíveis, nem estritamente necessárias, mas isso não significa que medidas possam deixar de ser feitas: sempre se deve procurar consegui-las e da melhor forma possível.)

\section{DIAgNÓSTICO}

O diagnóstico de uma PVC (ou de um torcicolo) começa pela queixa e, ou pela observação. No caso em que a queixa aparece, a idade e, ou as condições de aparecimento são muito indicativas do fator causal. Problemas ortopédicos, por exemplo, fusões de vértebras, contraturas ou encurtamentos musculares, são de surgimento imediato ao nascimento, e mais precocemente notados do que os de origem visual.

Ao exame, causas ortopédicas mostram movi- o ângulo de estrabismo for diferente (maior ou menor), o outro olho deve também ser operado.

Por exemplo, supondo-se uma ETOE, cujo ângulo de desvio coincida com o da PVC (Figura 8a), a cirurgia (e.g., recuo de RM, ressecção de RL) será feita apenas no olho direito, até valores de umas $50^{\Delta}$. Para valores maiores (Figura 8b), a cirurgia estender-se-á ao OE, procurando-se corrigir, nele, um ângulo de esotropia, na quantidade em que o desvio total $(\mathrm{S})$ exceder o do olho fixador relativamente à sua órbita $(\mathrm{H})$, isto é, $\mathrm{L}=\mathrm{S}-\mathrm{H}$. $\mathrm{Ou}$, em outras palavras, esse ângulo de esotropia é o do olho não fixador, relativamente à sua órbita (L, Figura 8b). Assim, também, se o ângulo de estrabismo for menor do que o da PVC (Figura 8c), a correção desta continuará a ser feita pelo desvio do olho fixador relativamente à sua órbita (esotropia igual a "H", Figura 8c), isto é, sobre um valor que excede o da totalidade do estrabismo (S). Claro, então, que a cirurgia cabível sobre o outro olho será a de correção de uma exotropia, isto é, a do desvio do OE relativamente à sua órbita (L).

mentos (voluntários ou passivos) da cabeça restringidos, enquanto, nas causas visuais, eles estão livres. Quando a cabeça é posta em sua situação normal ("ereta e em frente") e, melhor ainda, quando em posição oposta à viciosa, um estrabismo relacionado à PVC torna-se máximo; ou um nistagmo mais intenso (amplitude maior), facilitando o diagnóstico.

\section{TRATAMENTO}

Uma vez detectada a causa do torcicolo ou PVC, o tratamento objetivará eliminá-la. Se por problemas ortopédicos, o encaminhamento ao especialista deve ser feito. Se por um estrabismo, a cirurgia deve, obrigatoriamente, ser realizada sobre o olho fixador, procurando-se corrigir em seus músculos a magnitude angular com que ele se mantém desviado relativamente à órbita respectiva. Se
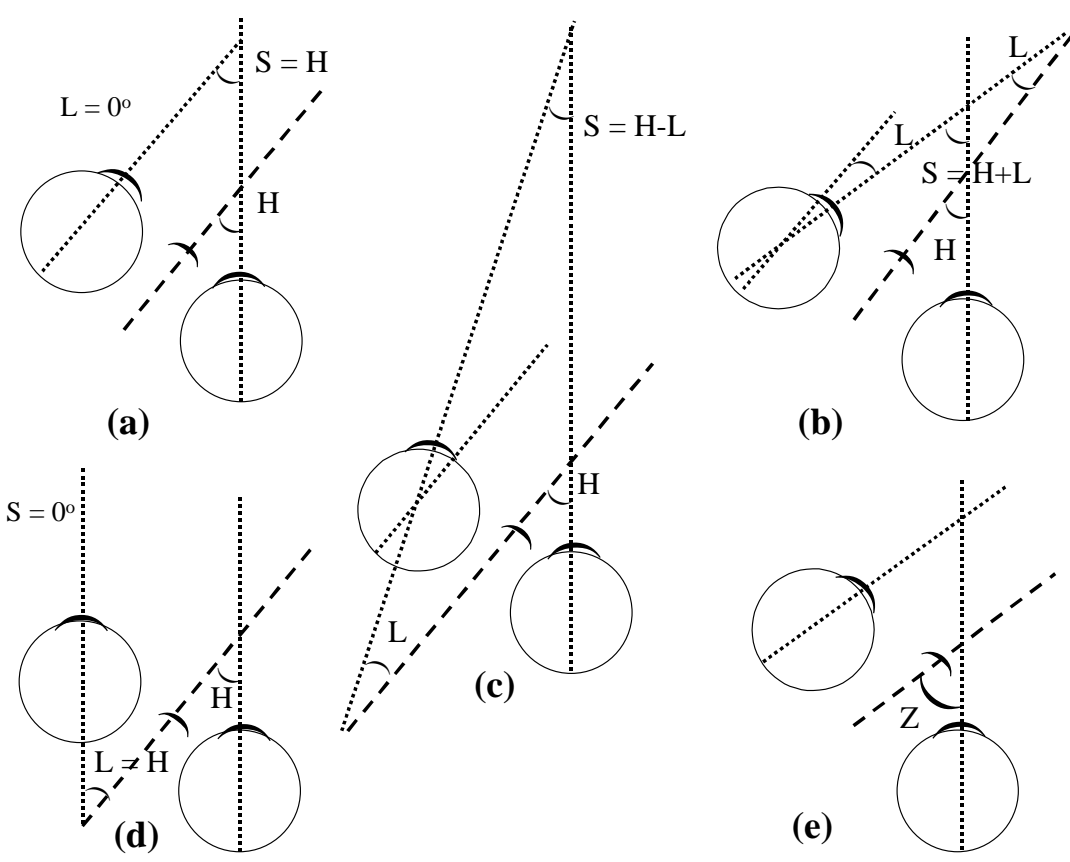

Figura 8 - Esquemas de posições viciosas de cabeça para fixações oculares em levoversão, mostrando os desvios da cabeça (H ou Z), o do OE relativamente à sua órbita $(L)$ e o dele relativamente ao outro, isto é, o ângulo de estrabismo $(S=H+L)$ : a) ETOE igual à PVC; b) ETOE maior que a PVC; c) ETOE menor que a PVC; d) PVC sem estrabismo; e) PVC muito acentuada, com ângulo de desvio (Z) maior do que o corrigível com cirurgia monocular. 
Iguais raciocínios são aplicáveis a quaisquer outros casos: o desvio a ser corrigido é o do olho sobre o qual se opera, relativamente à sua órbita. Em casos de PVC para bloqueio de nistagmos, sem estrabismo (Figura 8d), a correção é a de uma esotropia num olho (no caso o OD) e a de uma exotropia no outro (no caso o $\mathrm{OE}$ ) em iguais magnitudes.
Finalmente, se o ângulo de uma PVC for maior do que um que se possa corrigir com procedimentos sobre um dos olhos (Figura 8e), a distribuição de operações por ambos poderá conseguir a neutralização do estrabismo, ainda que uma PVC residual (determinada pela insuficiência quantitativa de uma correção monocular) fique prognosticada.

BICAS HEA. Ocular torticollis. Compensatory head postures. Medicina, Ribeirão Preto, 33: 64-72, jan./march 2000.

ABSTRACT: Torticollis and compensatory head postures are terms indifferently applied to describe a deviation of the head relatively to the body. This may be due to orthopaedic defects (of cervical vertebras, muscular contractures) or ocular causes which represent adjustments for compensation of oculomotor imbalances (incomitant strabismus or heterophorias, blockade of nistagmus, fixation by an eye deviated in its orbit, blepharoptosis and others, less frequent). The quantification of a head posture evokes the need of an analysis about conceptual (criteria and referentials) and operational related problems.

The differential diagnosis between orthopaedic and ocular causes is reached by the examination of passive movements of the head relatively to the body and by those of the oculomotor balance (cover test, ocular rotations). Since an ocular cause is proved, its correction depends on a specifically directed surgical procedure, basically that of an adequate repositioning of the fixating eye in its orbit and that of neutralization of an angle of strabismus if it is present. Several practical cases are then commented.

UNITERMS: Ocular Motility Disorders. Optical Rotation. Strabismus. 